\title{
PROFILE OF BACTERIAL ISOLATES IN NEONATAL BLOOD CULTURE AND THEIR ANTIBIOTIC SUSCEPTIBILITY PATTERNS (ANTIBIOGRAM) IN NEONATAL SEPSIS AT A TERTIARY CARE HOSPITAL NICU IN SOUTH INDIA
}

\author{
D. Annapurna ${ }^{1}$, P. Ramu², P. Rakesh ${ }^{3}$
}

${ }^{1}$ Associate Professor, Department of Pharmacology, Rangaraya Medical College, Kakinada.

${ }^{2}$ Associate Professor, Department of Paediatrics, Government Medical College, Ananthapuramu.

3Postgraduate Student, Department of Paediatrics, Andhra Medical College, Visakhapatnam.

\begin{abstract}
BACKGROUND
ABSTRACT

Neonatal sepsis is one of the major causes of morbidity and mortality in neonates. The spectrum of bacterial pathogens causes Neonatal sepsis and their antibiotic sensitivity patterns vary from hospital to hospital. The objectives of this study is to detect the bacterial profile in Neonatal sepsis and their antibiotic sensitivity pattern in neonates admitted in our Neonatal Intensive Care Unit (NICU).
\end{abstract}

\section{MATERIALS AND METHODS}

This is a descriptive study carried out in the NICU of Department of Paediatrics- Andhra Medical College- King George HospitalVisakhapatnam between July 2016 and December 2016 (6 months). During the study period, blood specimens for culture were drawn from 304 patients admitted for suspected Neonatal sepsis. Neonates were evaluated for bacterial aetiological agents by blood culture and their antimicrobial sensitivity pattern was analysed.

\section{RESULTS}

The Blood culture was positive in 51.97\% (158/304) of neonates with suspected sepsis, of which 59.49\% (94/158) isolates were Gram-negative organisms. The common isolates were Klebsiella (25.95\%), S. aureus (20.25\%) and E. coli (13.29\%). Both Gramnegative and Gram-positive organisms were found resistant to commonly used antibiotics such as Ampicillin, Cefotaxime and Ceftriaxone. Majority of the isolates in our study showed highest sensitivity to Piperacillin + Tazobactam, Gentamicin and Cefoperazone + Sulbactam.

\section{CONCLUSION}

Our study revealed Gram-negative organisms constituted the major group of isolates and Klebsiella being the most predominant organism causing neonatal sepsis in our institute. Both Gram-negative and Gram-positive organisms were found resistant to commonly used antibiotics. Hence, we suggest the institute should formulate an antibiotic policy regarding rational use of antibiotics and implement a surveillance programme on antibiotic resistance.

\section{KEYWORDS}

NICU (Neonatal Intensive Care Unit), Neonatal Sepsis, Blood Culture, Sensitivity, Resistance, Antibiotics, Gram-Negative Bacteria, Gram-Positive Bacteria, Antibiogram.

HOW TO CITE THIS ARTICLE: Annapurna D, Ramu P, Rakesh P. Profile of bacterial isolates in neonatal blood culture and their antibiotic susceptibility patterns (antibiogram) in neonatal sepsis at a tertiary care hospital NICU in South India. J. Evolution Med. Dent. Sci. 2018;7(02):249-255, DOI: $10.14260 /$ jemds/2018/56

\section{BACKGROUND}

Neonatal Sepsis refers to an infant (aged $<28$ days) who is ill and from whom a pathogen is recovered (or strongly suspected if this is not possible). The presence of clinical illness distinguishes this condition from bacteraemia alone. Neonatal sepsis is diagnosed when generalised systemic features are associated with pure growth of the bacteria from one or more sites. When clinical and laboratory findings are consistent with bacterial infection but blood culture is sterile, infants are labelled to have "probable sepsis." Neonatal sepsis

'Financial or Other Competing Interest': None.

Submission 28-11-2017, Peer Review 22-12-2017,

Acceptance 28-12-2017, Published 08-01-2018.

Corresponding Author:

Dr. P. Ramu,

Raja Sagi Residency $\mathrm{FF}_{3}$,

D. No.14-1-122/13,

Nowroji Road, Maharanipeta,

Visakhapatnam-530002, Andhra Pradesh.

E-mail: drpramu73@gmail.com

DOI: $10.14260 /$ jemds $/ 2018 / 56$

\section{(c) $(i)(2)$}

can be divided into two main subtypes (Early onset septicaemia and Late onset septicaemia) depending on whether the onset is during the first 72 hours of life or later. Globally, 130 million babies are born every year and of these 4 million babies die during the new-born period i.e. first four weeks of life. Almost, $99 \%$ of neonatal deaths occur in developing countries. India accounts for highest number of annual births ( 27 million) and neonatal deaths (1.2 million or $30 \%$ of global burden). ${ }^{1}$ The incidence of sepsis in the neonatal period varies from 1 to 8 cases per 1,000 live births in United States. ${ }^{2}$ According to WHO 2000 estimates the main direct causes of neonatal deaths include preterm births (27\%), severe infections (36\%), birth asphyxia (23\%) and congenital malformations (7\%). According to pooled hospital data based on NNPD (National Neonatal Perinatal Database) survey, the incidence of neonatal sepsis is around 30 per 1000 live births.

Early onset septicaemia is caused by organisms prevalent in the genital tract or in the labour room and maternity operation theatre. In the west early onset infection are mostly caused by Group B Streptococci and E. coli, while in our setup 
most cases are due to Gram-negative organisms, especially E. coli, Klebsiella and Enterobacter species. Late onset septicaemia (LOS) is acquired as nosocomial infection from the nursery or lying in ward. About two-third cases of late onset septicaemia are caused by Gram-negative bacilli such as Klebsiella pneumonia, Enterobacteria, Escherichia coli, Pseudomonas aeruginosa and Proteus species while the rest are contributed by Gram positive organisms including coagulase positive Staphylococcus aureus and coagulase negative Staphylococcus (CONS). Perinatal infections, especially neonatal bacterial sepsis is the commonest cause of neonatal mortality in India. Next to perinatal asphyxia and birth injuries, septicaemia in the new-born is a leading cause of neonatal morbidity and mortality. Diagnosis for neonatal sepsis fraught with poor specificity. Blood culture provides a definitive diagnosis for neonatal sepsis and should be taken before starting antimicrobial therapy.3,4 Laboratory evaluation of the symptomatic infants suspected of Early Onset Sepsis (EOS) includes minimum or Complete Blood Count (CBC) with differential count and blood culture. Other investigations may require more severely ill infants. For infants with strong clinical suspicion of sepsis, a Lumbar Puncture (LP) for Cerebrospinal Fluid (CSF) cell count, protein and glucose concentration, Gram stain and culture should be performed before administration of antibiotics if the infant is clinically unstable or if later culture results or clinical course demonstrate that sepsis was present. ${ }^{4}$

Evaluation of the asymptomatic infants at risk of EOS [these infants include those born to mothers who have received inadequate antibiotic prophylaxis for Group B Streptococcus (GBS) and those born to mothers with suspected Chorioamnionitis] is also important, because they may have colonisation or bacteraemia that places them at risk for development of symptomatic EOS. Blood cultures are the definitive determination of bacteraemia. A number of Laboratory tests have been evaluated for their ability to predict at-risk infants (will go onto develop symptomatic or culture proven sepsis, but no single test has adequate sensitivity and specificity).

With advances in the development of computer assisted continuous read culture systems, most blood cultures will be positive within 24 to 36 hours of incubation if organisms are present. Most institutions empirically treat infants for sepsis for a minimum of 48 hours with the assumption that true positive cultures will turn positive within that period. At least $0.5 \mathrm{~mL}$ (and preferably $1 \mathrm{~mL}$ ) of blood should be placed in most paediatric blood culture bottles and two culture bottles are used, one for aerobic culture and one for anaerobic culture. Certain organisms causing EOS such as Bacteroides fragilis will only grow under anaerobic conditions. Additionally, GBS, Staphylococcal species and many Gramnegative organisms grow in a facultative fashion, and the use of two culture bottles increase the likelihood of detecting low level bacteraemia with these organisms. Institution of prompt treatment is essential for ensuring optimum outcome of neonates with sepsis who often reach the health care facility late and in a critical condition. Supportive care and antibiotics are the two equally important components of treatment in neonatal sepsis. In a seriously sick neonate suspected of sepsis, appropriate antibiotic therapy should be initiated without any delay after obtaining blood samples for culture and sepsis screen.3,4 The empirical therapy of neonatal sepsis should cover the major causative pathogens, while awaiting reports of culture studies. It is important to remember that bacterial flora is dynamic and different from one place to the other and it changes in the same place over a period of time. It is essential to closely monitor the bacterial flora of the NICU and the antibiotic sensitivity pattern of pathogens to evolve rational antibiotic policy, which is most suitable and specific for a particular NICU.3,4 Antibiogram is a periodic summary of antimicrobial susceptibilities of local bacterial isolates and are often used by clinicians to assess local susceptibility rates as an aid in selecting empiric antibiotic therapy and in monitoring resistance trends over time within an institution. ${ }^{5}$ Antibiograms can also be used to compare susceptibility rates across institutions and track resistance trends. The percentage susceptibility of the most frequently isolated bacteria should be presented in the antibiogram, preferably in a tabular form. ${ }^{5}$ Making an antibiogram is the first step before framing the antibiotic policy. ${ }^{5}$ Hence, we studied the profile of bacterial isolates in neonatal blood culture and their antibiotic susceptibility patterns (antibiogram) in neonatal sepsis in our institute.

\section{MATERIALS AND METHODS}

This is a descriptive study carried out in the NICU of Department of Paediatrics- Andhra Medical College- King George Hospital- Visakhapatnam between July 2016 and December 2016 (6 months). The study included all neonates aged 0 - 28 days of life with primary diagnosis of Neonatal sepsis (both confirmed and suspected cases) admitted in our NICU during the study period. Babies aged more than 28 days of life and neonates with other serious complications were excluded from our study. Data such as age, sex, birth weight, gestational age, symptoms and clinical signs were recorded in our institutional case sheet. Neonates with suspected sepsis were investigated as per the protocol (includes Sepsis screen and Blood culture). Blood samples were collected with proper antiseptic precautions and sent to the Microbiology Department of our institute where they do follow standard scientific procedure for Blood cultures. Parameters related to Blood culture such as positivity of culture, isolated organisms, Gram +ve/ Gram-ve, sensitivity and resistance pattern to various antibiotics (Antibiogram) were recorded and statistical analysis was done regarding frequency and percentages. These results were presented in pie charts and Bar diagrams wherever necessary.

\section{RESULTS}

The common isolates in our study were Klebsiella (25.95\%), Staphylococcus aureus (20.25\%) and E. coli (13.29\%), and other isolates such as pseudomonas $(12.66 \%)$ coagulasenegative staphylococci (10.76\%), Methicillin-resistant Staph aureus $(9.50 \%)$, Acinetobacter $(3.16 \%)$ and proteus $(4.43 \%)$ were identified in the present study (Table 1).

Table 2 shows frequency of Gram-negative organisms isolated by blood culture of neonates with sepsis in the present study ( $\mathrm{n}=158)$.

Table 3 shows frequency of Gram-positive organisms isolated by blood culture of neonates with sepsis in the 
present study $(\mathrm{n}=158)$. Table 4 displays the "antibiogram" [Summary of antimicrobial susceptibilities (sensitivity/ resistance) among bacterial isolates of blood culture from new-borns with sepsis] of our study.

Table 5 shows the antibiotic "sensitivity" pattern among "Gram-positive" bacterial isolates in the present study. $62.5 \%$ (20/32), 50\% (16/32) and 40.62\% (13/32) of Staph. aureus isolates were found sensitive to Vancomycin, Cefoperazone + Sulbactam and Tobramycin respectively. About 53.33\% (8 out of 15) MRSA strains were sensitive to linezolid and ofloxacin in the present study. 70.58\% (12/17) CONS isolates in the present study were found sensitive to Vancomycin.

Table 6 shows the antibiotic "resistance" pattern among "Gram-positive" bacterial isolates in the present study. 25\% (8/32) of Staph. aureus, $40 \%$ (6/15) of MRSA isolates were found to be resistant to Ampicillin and 40\% (6/15) of MRSA were found to be resistant to Vancomycin also.

Table 7 shows the antibiotic "sensitivity" pattern among "Gram-negative" bacterial isolates in the present study. Cefoperazone/Sulbactam, Piperacillin/Tazobactam and Gentamycin were the three most effective antibiotics against all the five types of Gram-negative organisms mentioned in the present study.

Table 8 shows resistance pattern of various organisms against common antibiotics. In our study, we found the following organisms namely Klebsiella 29 (70.73\%), E. coli 18 (85.7\%), Pseudomonas 8 (40.0\%), Proteus 6 (85.71\%) and Acinetobacter 4 (80.0\%) were resistant to Ampicillin.

\begin{tabular}{|c|c|c|}
\hline Organism Name & Number & Percentage \\
\hline Klebsiella & 41 & 25.95 \\
\hline Staph. aureus & 32 & 20.25 \\
\hline E. coli & 21 & 13.29 \\
\hline Pseudomonas & 20 & 12.66 \\
\hline CONS & 17 & 10.76 \\
\hline MRSA & 15 & 9.50 \\
\hline Proteus & 7 & 4.43 \\
\hline Acinetobacter & 5 & 3.16 \\
\hline Total & 158 & 100 \\
\hline
\end{tabular}

\begin{tabular}{|c|c|c|}
\hline Organism Name & Number & Percentage \\
\hline Klebsiella & 41 & 25.95 \\
\hline E. coli & 21 & 13.29 \\
\hline Pseudomonas & 20 & 12.66 \\
\hline Proteus & 7 & 4.43 \\
\hline Acinetobacter & 5 & 3.16 \\
\hline Total & 94 & 59.49 \\
\hline
\end{tabular}

Table 2. Frequency of Gram-Negative Organisms Isolated by Blood Culture of Neonates with Sepsis in the Present Study (n= 158)

\begin{tabular}{|c|c|c|}
\hline Organism Name & Number & Percentage \\
\hline Staph. aureus & 32 & 20.25 \\
\hline MRSA & 15 & 9.5 \\
\hline CONS & 17 & 10.76 \\
\hline Total & 64 & 40.51 \\
\hline
\end{tabular}

Table 3. Frequency of Gram-Positive Organisms Isolated by Blood Culture of Neonates with Sepsis in the Present Study (n= 158)

\begin{tabular}{|c|c|c|c|c|c|c|c|c|}
\hline Antibiotic & $\begin{array}{c}\text { Klebsiella } \\
(n=41) S / R\end{array}$ & $\begin{array}{c}\text { Staph. aureus } \\
(n=32) S / R\end{array}$ & $\begin{array}{c}\text { E. coli } \\
(n=21) S / R\end{array}$ & $\begin{array}{c}\text { Pseudomonas } \\
(n=20) S / R\end{array}$ & \begin{tabular}{|c|} 
Proteus \\
$(n=7) S / R$
\end{tabular} & $\begin{array}{c}\text { Acinetobacter } \\
(n=5) S / R\end{array}$ & $\begin{array}{c}\text { CONS } \\
(n=17) S / R\end{array}$ & $\begin{array}{c}\text { MRSA } \\
(n=15) ~ S / R\end{array}$ \\
\hline Ampicillin & $-/ 26$ & $4 / 8$ & $2 / 18$ & \begin{tabular}{|l|}
$3 / 8$ \\
\end{tabular} & $1 / 6$ & $1 / 4$ & $2 / 8$ & $-/ 6$ \\
\hline Amoxicillin & - & $-/ 2$ & - & $-/ 2$ & $-/ 2$ & $-/ 2$ & - & $-/ 2$ \\
\hline Amoxiclav & $-/ 14$ & - & $-/ 12$ & $2 / 4$ & $-/ 4$ & $-/ 2$ & $-/ 4$ & $2 /-$ \\
\hline Cefixime & $13 / 6$ & $4 / 2$ & $4 / 6$ & $2 / 2$ & - & - & $-/ 2$ & $-/ 4$ \\
\hline Cefotaxime & $-/ 6$ & $-/ 2$ & - & $2 /-$ & - & $-/ 4$ & - & $2 /-$ \\
\hline Ceftazidime & $14 / 6$ & $2 /-$ & $7 / 4$ & $6 / 2$ & - & $2 / 2$ & - & - \\
\hline Cefoxitin & $2 / 4$ & $10 / 8$ & - & $2 /-$ & - & - & $4 / 4$ & $4 / 8$ \\
\hline Ceftriaxone & $4 /-$ & $2 /-$ & $2 / 2$ & - & - & - & $-/ 2$ & $2 /-$ \\
\hline Cefpodoxime & $4 / 4$ & $-/ 4$ & $-/ 12$ & $2 / 2$ & $-/ 2$ & - & $-/ 4$ & - \\
\hline \begin{tabular}{|c|} 
Cefoperazone + \\
Sulbactam \\
\end{tabular} & $19 /-$ & $16 / 2$ & $14 / 2$ & $13 / 2$ & $5 /-$ & $2 /-$ & $6 /-$ & $2 /-$ \\
\hline Cephalexin & - & $2 /-$ & $-/ 1$ & - & - & - & - & - \\
\hline Ciprofloxacin & $-/ 2$ & $4 / 2$ & $4 / 2$ & $2 /-$ & - & - & $-/ 2$ & $6 / 2$ \\
\hline Cotrimoxazole & $4 / 2$ & - & $-/ 2$ & $-/ 2$ & - & - & $-/ 2$ & - \\
\hline Imipenem & $10 /-$ & $2 /-$ & $6 /-$ & $6 /-$ & $2 /-$ & $2 /-$ & - & $4 /-$ \\
\hline Gentamycin & $19 / 2$ & $6 / 2$ & $17 /-$ & $13 /-$ & $6 /-$ & $6 /-$ & $8 /-$ & $-/ 4$ \\
\hline Levofloxacin & $4 /-$ & - & - & $4 /-$ & - & - & $2 /-$ & - \\
\hline Linezolid & - & $6 / 4$ & - & - & - & - & $4 /-$ & $8 / 2$ \\
\hline Clindamycin & $-/ 2$ & $2 / 4$ & - & - & - & - & $4 /-$ & $2 / 2$ \\
\hline Azithromycin & $2 /-$ & $12 /-$ & - & $4 /-$ & - & - & $4 / 2$ & $6 /-$ \\
\hline Meropenem & $7 /-$ & $2 /-$ & $8 /-$ & $4 /-$ & $2 /-$ & $2 /-$ & - & - \\
\hline Amikacin & - & - & - & $2 /-$ & - & - & - & $2 /-$ \\
\hline Ofloxacin & $5 / 2$ & $8 /-$ & $2 /-$ & - & - & - & $4 / 2$ & $8 /-$ \\
\hline Tetracycline & - & $16 /-$ & - & - & - & - & $6 / 2$ & $4 /-$ \\
\hline Tigecycline & - & $6 / 2$ & - & - & - & - & $2 /-$ & $6 /-$ \\
\hline Teicoplanin & $-/ 2$ & $10 / 2$ & - & $4 /-$ & - & - & $6 /-$ & $2 / 2$ \\
\hline $\begin{array}{c}\text { Piperacillin + } \\
\text { tazobactam }\end{array}$ & $3 / 2$ & $6 /-$ & $19 /-$ & $15 / 2$ & $6 /-$ & $4 /-$ & $2 /-$ & $2 /-$ \\
\hline Tobramycin & $4 / 2$ & $12 / 2$ & $2 /-$ & $2 /-$ & - & $2 /-$ & $7 /-$ & $4 /-$ \\
\hline Vancomycin & $-/ 2$ & $20 / 2$ & - & $4 /-$ & - & - & $12 /-$ & $6 / 6$ \\
\hline
\end{tabular}




\begin{tabular}{|c|c|c|c|}
\hline Antibiotics & \begin{tabular}{|c|} 
Staph. \\
aureus \\
Number (\%)
\end{tabular} & $\begin{array}{c}\text { MRSA } \\
\text { Number (\%) }\end{array}$ & $\begin{array}{c}\text { CONS } \\
\text { Number (\%) }\end{array}$ \\
\hline Ampicillin & $4(12.5 \%)$ & - & $2(11.76 \%)$ \\
\hline Cefotaxime & - & $2(13.33 \%)$ & - \\
\hline Ceftazidime & $2(6.25 \%)$ & - & - \\
\hline Ceftriaxone & $2(6.25 \%)$ & $2(13.33 \%)$ & - \\
\hline $\begin{array}{c}\text { Cefoperazone+ } \\
\text { Sulbactam }\end{array}$ & $16(50 \%)$ & $2(13.33 \%)$ & $6(5.29 \%)$ \\
\hline Ciprofloxacin & $4(12.5 \%)$ & $6(40 \%)$ & - \\
\hline Gentamycin & $6(18.75 \%)$ & - & $8(47.05 \%)$ \\
\hline Meropenem & $2(6.25 \%)$ & - & - \\
\hline Ofloxacin & $8(25 \%)$ & $8(53.33 \%)$ & $4(23.52 \%)$ \\
\hline Tigecycline & $6(18.75 \%)$ & $6(40 \%)$ & $2(11.76 \%)$ \\
\hline Teicoplanin & $10(31.25 \%)$ & 213.33\%) & $6(5.29 \%)$ \\
\hline Pipzo & $6(18.75 \%)$ & $213.33 \%)$ & $2(11.76 \%)$ \\
\hline Tobramycin & $13(40.62 \%)$ & $4(26.67 \%)$ & 7 (41.17\%) \\
\hline Vancomycin & $20(62.5 \%)$ & $6(40 \%)$ & $12(70.58 \%)$ \\
\hline Linezolid & $6(18.75 \%)$ & $8(53.33 \%)$ & $4(23.52 \%)$ \\
\hline Clindamycin & $2(6.25 \%)$ & $2(13.33 \%)$ & $4(23.52 \%)$ \\
\hline \multicolumn{4}{|c|}{$\begin{array}{c}\text { Table 5. Antibiotic "Sensitivity" Pattern among "Gram } \\
\text { Positive" Bacterial Isolates of Neonatal Blood Culture in } \\
\text { the Present Study }\end{array}$} \\
\hline
\end{tabular}

MRSA: Methicillin-resistant Staph. aureus, CONS: Coagulase negative Staphylococci.

\begin{tabular}{|c|c|c|c|}
\hline Antibiotic & $\begin{array}{c}\text { Staph. } \\
\text { aureus n (\%) }\end{array}$ & $\begin{array}{c}\text { MRSA } \\
\text { n (\%) }\end{array}$ & $\begin{array}{c}\text { CONS } \\
\text { n (\%) }\end{array}$ \\
\hline Ampicillin & $8(25 \%)$ & $6(40 \%)$ & $8(47.5 \%)$ \\
\hline Cefotaxime & $2(6.25 \%)$ & - & 0 \\
\hline Ceftazidime & $6(18.75 \%)$ & - & 0 \\
\hline Ceftriaxone & 0 & - & $2(11.76 \%)$ \\
\hline $\begin{array}{c}\text { Cefoperazone+ } \\
\text { Sulbactam }\end{array}$ & $2(6.25 \%)$ & - & 0 \\
\hline Ciprofloxacin & $2(6.25 \%)$ & $2(13.33 \%)$ & $2(11.76 \%)$ \\
\hline Gentamycin & $2(6.25 \%)$ & $4(26.67 \%)$ & 0 \\
\hline Meropenem & 0 & - & 0 \\
\hline Ofloxacin & 0 & - & $2(11.76 \%)$ \\
\hline Tigecycline & $2(6.25 \%)$ & - & 0 \\
\hline Teicoplanin & $2(6.25 \%)$ & $2(13.33 \%)$ & 0 \\
\hline Pipzo & 0 & - & 0 \\
\hline Tobramycin & $2(6.25 \%)$ & - & 0 \\
\hline Vancomycin & $2(6.25 \%)$ & $6(40 \%)$ & 0 \\
\hline Linezolid & $4(12.5 \%)$ & $2(13.33 \%)$ & 0 \\
\hline Clindamycin & $4(12.5 \%)$ & $2(13.33 \%)$ & 0 \\
\hline $\begin{array}{c}\text { Table 6. Antibiotic “Resistance" Pattern among “Gram } \\
\text { Positive" Bacterial Isolates of Neonatal Blood } \\
\text { Culture in the Present Study }\end{array}$ \\
\hline
\end{tabular}

\begin{tabular}{|c|c|c|c|c|c|}
\hline Antibiotic & $\begin{array}{c}\text { Klebsiella } \\
n=41\end{array}$ & $\begin{array}{c}\text { E. coli } \\
\mathbf{n}=21\end{array}$ & $\begin{array}{c}\text { Pseudomonas } \\
\mathbf{n}=20\end{array}$ & $\begin{array}{c}\text { Proteus } \\
\mathbf{n}=7\end{array}$ & $\begin{array}{c}\text { Acinetobacter } \\
n=5\end{array}$ \\
\hline Ampicillin & - & $2(9.52 \%)$ & $3(15 \%)$ & $1(14.28 \%)$ & 1 \\
\hline Cefotaxime & - & - & $2(10 \%)$ & - & - \\
\hline Ceftazidime & $14(34.14 \%)$ & $7(33.33 \%)$ & $6(30 \%)$ & - & $2(40 \%)$ \\
\hline Ceftriaxone & $4(9.75 \%)$ & $2(9.52 \%)$ & - & - & - \\
\hline $\begin{array}{l}\text { Cefoperazone + } \\
\text { Sulbactam }\end{array}$ & $19(46.34 \%)$ & $14(66.66 \%)$ & $13(65 \%)$ & $\begin{array}{c}5 \\
(71.42 \%) \\
\end{array}$ & $2(40.0 \%)$ \\
\hline Ciprofloxacin & & $4(19.04 \%)$ & $2(10 \%)$ & - & - \\
\hline Gentamycin & $19(46.34 \%)$ & $17(80.95 \%)$ & $13(65 \%)$ & $6(85.71 \%)$ & $5(100 \%)$ \\
\hline Meropenem & $7(17.07 \%)$ & $8(38.09 \%)$ & $4(20 \%)$ & $2(28.57 \%)$ & 2 \\
\hline Ofloxacin & $5(12.19 \%)$ & $2(9.52 \%)$ & - & - & - \\
\hline Tigecycline & - & - & - & - & - \\
\hline Teicoplanin & - & - & $4(20 \%)$ & - & - \\
\hline Piperacillin + Tazobactam & $31(75.60 \%)$ & $19(90.47 \%)$ & $15(75 \%)$ & $6(85.71 \%)$ & $4(80.0 \%)$ \\
\hline Tobramycin & $4(9.75 \%)$ & $2(9.52 \%)$ & $2(10.0 \%)$ & - & $2(40.0 \%)$ \\
\hline Vancomycin & - & - & $4(20 \%)$ & - & - \\
\hline Linezolid & - & - & - & - & - \\
\hline Clindamycin & - & - & - & - & - \\
\hline \multicolumn{6}{|c|}{$\begin{array}{l}\text { Table 7. Antibiotic 'Sensitivity" Pattern among "Gram Negative" } \\
\text { Bacterial Isolates of Neonatal Blood Culture in the Present Study }\end{array}$} \\
\hline
\end{tabular}

\begin{tabular}{|c|c|c|c|c|c|}
\hline Antibiotic & $\begin{array}{c}\text { Klebsiella } \\
\mathbf{n = 4 1}\end{array}$ & $\begin{array}{c}\text { E. coli } \\
\mathbf{n = 2 1}\end{array}$ & $\begin{array}{c}\text { Pseudomonas } \\
\mathbf{n = 2 0}\end{array}$ & $\begin{array}{c}\text { Proteus } \\
\mathbf{n = 7}\end{array}$ & $\begin{array}{c}\text { Acinetobacter } \\
\mathbf{n = 5}\end{array}$ \\
\hline Ampicillin & 29 & 18 & 6 & 6 \\
$(70.73)$ & $(85.71)$ & - & - & $4(80 \%)$ \\
\hline Cefotaxime & $6(14.63)$ & - & $2(10 \%)$ & - & $4(80 \%)$ \\
\hline Ceftazidime & $6(14.63)$ & $4(19.04)$ & - & - & $2(40 \%)$ \\
\hline Ceftriaxone & - & $2(9.52)$ & $2(10 \%)$ & - & - \\
\hline $\begin{array}{c}\text { Cefoperazone } \\
\text { Sulbactam }\end{array}$ & - & $2(9.52)$ & - & - & - \\
\hline Ciprofloxacin & $2(4.87)$ & $2(9.52)$ & - & - & - \\
\hline Gentamycin & $2(4.87)$ & - & - & - & - \\
\hline Meropenem & - & - & - & - & - \\
\hline Ofloxacin & $2(4.87)$ & - & - & - & - \\
\hline Tigecycline & - & - & $2(10 \%)$ & & - \\
\hline Teicoplanin & $2(4.87)$ & - & - & - & - \\
\hline Pipzo & $2(4.87)$ & - & & - \\
\hline
\end{tabular}




\begin{tabular}{|c|l|l|l|l|l|}
\hline Tobramycin & $2(4.87)$ & - & - & - & - \\
\hline Vancomycin & $2(4.87)$ & - & - & - & - \\
\hline Linezolid & $4(9.75)$ & - & - & - & - \\
\hline Clindamycin & $2(4.87)$ & - & - & - & - \\
\hline \multicolumn{7}{|c|}{ Table 8. Antibiotic “Resistance" Pattern among “Gram Negative” } \\
Bacterial Isolates of Neonatal Blood Culture in the Present Study \\
\hline
\end{tabular}
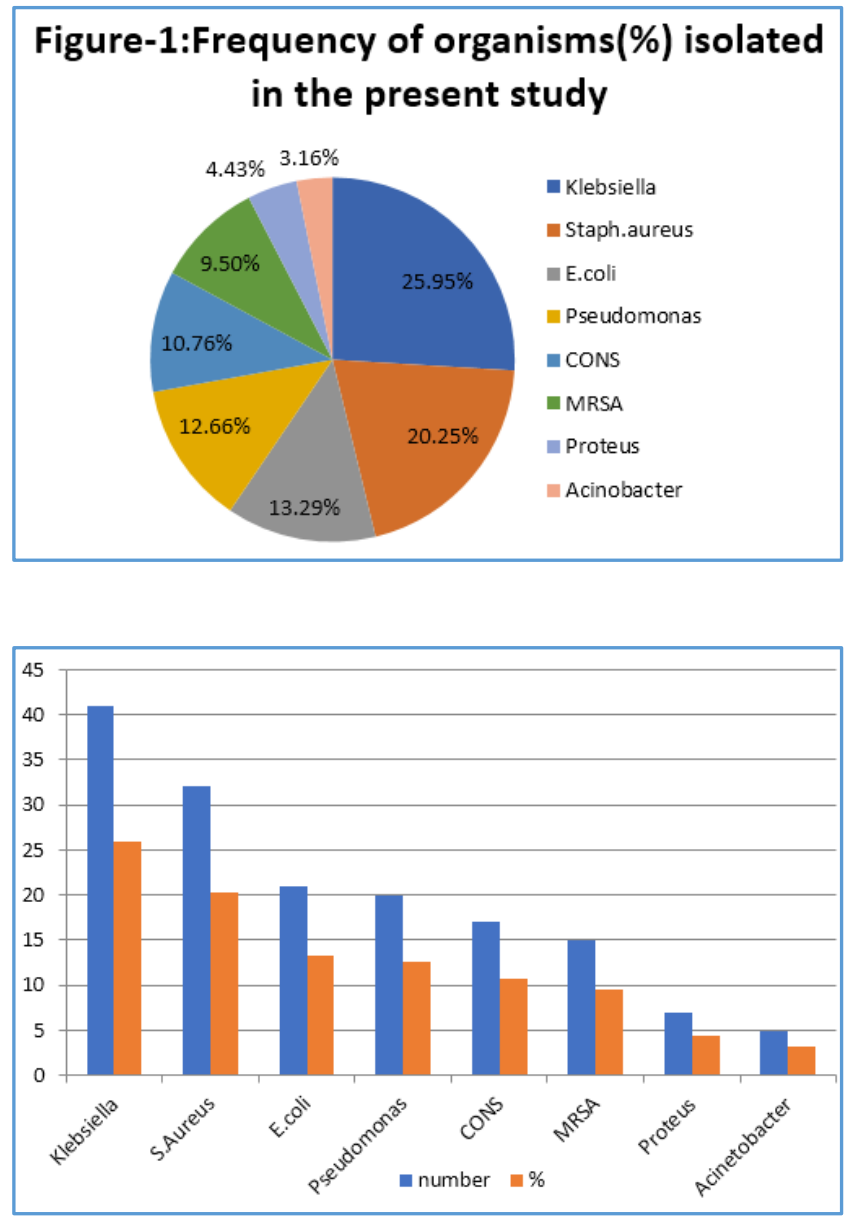

Figure 2. Bar Diagram showing Frequency of Organisms (In Number and \%) Isolated in the Present Study

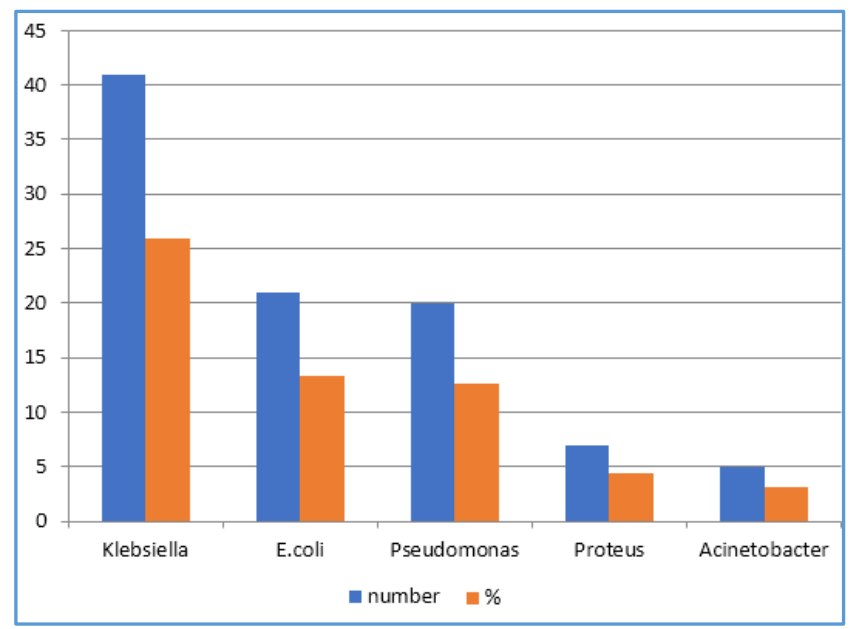

Figure 3. Bar Diagram showing Frequency of GramNegative Organisms Isolated in the Present Study

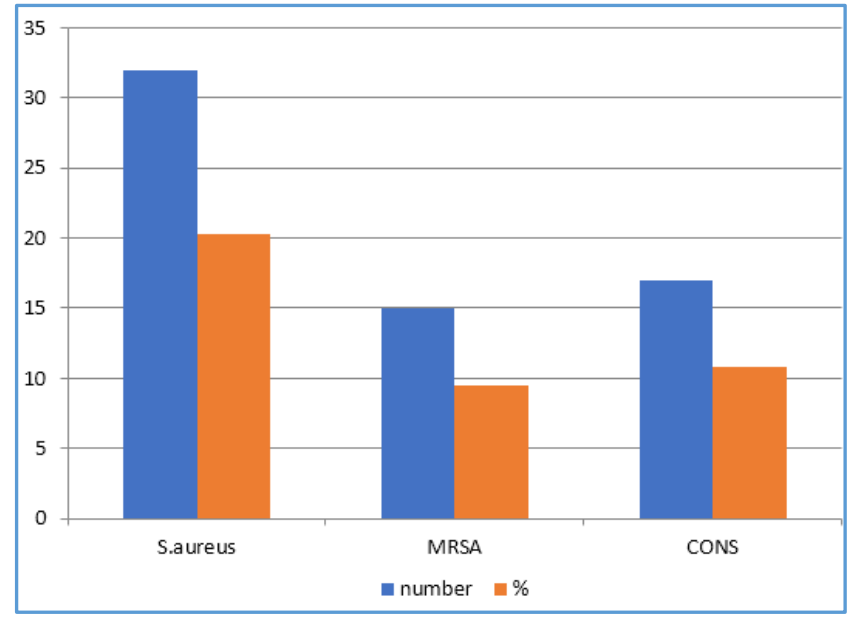

Figure 4. Bar Diagram showing Frequency of GramPositive Organisms Isolated in the Present Study

\section{DISCUSSION}

Since the antimicrobial spectrum and susceptibility profile is different in different settings, there cannot be a universal policy of empirical regimen. Antibiotics are often used in neonates on slightest suspicion of sepsis, because of grave and fulminant nature of neonatal sepsis. But unbridled over use of antibiotics is associated with serious risk of emergence of resistance strains of pathogens. Most new-born units in a country are facing the problem of overwhelming resistance to practically all antibiotics including third generation cephalosporins. ${ }^{4}$ Antimicrobial therapy can be made specific on a positive culture and sensitivity reporting available. However, this would be known only after 2 - 3 days, even in the best institutions only approximately one-fourth of babies suspected of sepsis have positive blood culture. ${ }^{4}$ Rational use of antibiotics is therefore the responsibility of every physician. Each treating unit should adopt a suitable policy. Based on changes in the spectrum of aetiological agents and the antibiotics sensitivity pattern, the choice of antibiotics must be periodically reviewed and modified. 4

During the study period, 304 new-born babies who had primary diagnosis of neonatal sepsis were admitted. The culture positivity rate in the present study was $51.97 \%$ (158/304) out of 158 organisms isolated 64 (40.51\%) were Gram-positive and 94 (59\%) were Gram-negative organisms, which was in agreement with Vaniya HV et $\mathrm{al}^{6}$ study (51\%), Shrestha et al ${ }^{7}$ study (44\%), Shahian et al ${ }^{8}$ study (43\%) and Thakur S et $\mathrm{al}^{9}$ study (North India- $42 \%$ ). Whereas in Meher et al ${ }^{10}$ study, they found culture positivity in $22.1 \%$ cases and Jyothi P et al11 found $19.2 \%$ culture positivity in their study.

In our study out of 304 total new-borns admitted with a diagnosis of Neonatal sepsis, 212 (69.74\%) babies were outborn and 92 (30.26\%) were inborn. This finding was in agreement with Shamiya NK et al ${ }^{12}$ study (Outborn $=75.4 \%$ and Inborn= 23\%).

In our study, 59.49\% (94/158) organisms isolated were Gram-negative and 40.51\% (64/158) were Gram-positive. 
This is comparable with studies reported by Vaniya HV et al, 6 Shrestha et al, ${ }^{7}$ Lamba $\mathrm{M}$ et al,13 Meher et al ${ }^{11}$ and Kayange et al. ${ }^{14}$ Predominance of Gram-negative organisms as high as $70 \%$ was found in Rehaman et al ${ }^{15}$ study.

The most common pathogens isolated from the blood culture of new-borns suffering from neonatal sepsis in the present study were Klebsiella pneumoniae (25.95\%), Staph. aureus (20.25\%), E. coli (13.29\%), Pseudomonas (12.66\%) and CONS (10.76\%). Klebsiella was the predominant organism isolated in Neonatal sepsis in previous studies reported by Vaniya $\mathrm{HV}$ et al, ${ }^{6}$ Shrestha et al, 7 Jyothi et al ${ }^{11}$ and Aletayeb et al.16 Whereas Pseudomonas and Staph. aureus were the predominant isolates in Neonatal sepsis in the studies done by Bhat et $\mathrm{al}^{17}$ and Mhada et $\mathrm{al}^{18}$ respectively. Dias et $\mathrm{al}^{19}$ and Shahian et $\mathrm{al}^{8}$ reported CONS as the predominant isolate in the studies done on Neonatal sepsis.

The analysis of Antibiogram of our study revealed decreased sensitivity among Gram-negative isolates against commonly used antibiotics such as Ampicillin, Amoxicillin, Amoxiclav and Cefotaxime and Ceftriaxone. This finding was in agreement with that of Vaniya et $\mathrm{al}^{6}$ study. This finding could be due to majority of our study neonates, $69.74 \%$ $(212 / 304)$ were outborn and ours is tertiary care hospital where we get cases referred from nearby 3 to 4 districts after initial few days of treatment. Gram-negative isolates in our study were found most sensitive to Gentamycin, Cefoperazone + Sulbactam and Piperacillin + Tazobactam. Only few Gram-negative isolates in our study were found sensitive to Ciprofloxacin and Ofloxacin. But in Vaniya et al ${ }^{6}$ study, their Gram-negative isolates were most sensitive to Ciprofloxacin (56.05\%) and Ofloxacin (60.09\%).

Antibiotics such as Tobramycin, Vancomycin and Cefoperazone + Sulbactam were most effective (with good susceptibility) against Staph. aureus and CONS (Grampositive isolates in our study), whereas MRSA isolates of our study were found most sensitive to Ofloxacin, Linezolid, Vancomycin and Tigecycline. In Jyothi et al ${ }^{11}$ and Vaniya et al ${ }^{6}$ studies, it was found that Gram-positive isolates were most sensitive to Linezolid.

In our study, Klebsiella, E. coli and Proteus isolates showed highest sensitivity to Piperacillin and Tazobactam. Pseudomonas isolates of our study showed highest sensitivity to Piperacillin and Tazobactam (75\%), Gentamycin and Cefoperazone + Sulbactam (65\%) each. This was in agreement with Vaniya et $\mathrm{al}^{6}$ study. In the studies done by Dias et al $^{19}$ and Rehman et al ${ }^{15}$ Ciprofloxacin was the most sensitive drug against Pseudomonas.

We found all the Acinetobacter isolates 5/5 (100\%) were sensitive to Gentamycin and $80 \%(4 / 5)$ were resistant to Ampicillin and Cefotaxime.

In our study, we found overall very few isolates (both Gram -ve and Gram +ve) were sensitive to Cefotaxime and Ceftriaxone.

Since our institute is a tertiary care hospital for nearby 3 to 4 districts, we do get more referral cases (outborn) who were already treated with antibiotics, complicated, seriously ill and often reach our facility late and in critical condition.

\section{CONCLUSION}

Our study revealed Gram-negative organisms constituted major group of isolates from new-borns admitted for neonatal sepsis and Klebsiella is the most predominant organism causing neonatal sepsis in our institute. Most of the organisms, both Gram-positive and Gram-negative were resistant to commonly used antibiotics such as Ampicillin, Cefotaxime and Ceftriaxone. Resistance developed even to higher antibiotics such as Vancomycin is of great concern. Therefore, we suggest an antibiotic policy should be formulated in the hospital and antibiotics should be used depending upon the antibiotic sensitivity pattern of the isolates. Unnecessary, injudicious or excessive use of antibiotics should be discouraged at all levels. The institute should implement a surveillance programme on antibiotic resistance. Further sensitisation of peripheral health care providers through local CME (Continuing Medical Education) programmes regarding the need of rational antibiotic therapy and antibiotic policy to prevent the emergence of antibiotic resistance.

\section{REFERENCES}

[1] Lawn JE, Counsens S, Zupan J. 4 million neonatal deaths: When? Where? Why? Lancet 2005;365(9462):891-900.

[2] Lukacs SL, Schoendorf KC, Schuchat A. Trends in sepsis related neonatal mortality in the United States, 1985-1998. Pediatr Infect Dis J 2004;23(7):599-603.

[3] Sankar MJ, Agarwal R, Deorari AK, et al. Sepsis in the newborn. Indian J Pediatr 2008;75(3):261-6.

[4] Ghai OP, Paul VK, Bagga A, et al. Essential paediatrics. $8^{\text {th }}$ edn. New Delhi, CBS publishers, 2014;8:162-5.

[5] Joshi S. Hospital antibiogram: a necessity. Indian J Med Microbiol 2010;28(4):277-80.

[6] Vaniya HV, Patel NM, Agrawal JM, et al. Antimicrobial culture sensitivity pattern in neonatal sepsis in a tertiary care hospital. Int J Med Sci Public Health 2016;5(4):661-5.

[7] Shrestha S, Shrestha NC, Dongal SS, et al. Bacterial isolates and its antibiotic susceptibility pattern in NICU. Kathmandu Univ Med J 2013;11(41):66-70.

[8] Shahian M, Pishva N, Kalani M. Bacterial etiology and antibiotic sensitivity patterns of early-late onset neonatal sepsis among newborns in Shiraz, Iran 20042007. IJMS 2010;35(4):293-8.

[9] Thakur S, Sood A, Thakur K, et al. Bacteriological profile of neonatal septicaemia in a rural tertiary care hospital in North India. Indian J Med Microbiol 2016;34(1):67-71.

[10] Mehar V, Yadav D, Somani P, et al. Neonatal sepsis in a tertiary care center in central India: microbiological profile, antimicrobial sensitivity pattern and outcome. J Neonatal Perinatal Med 2013;6(2):165-72.

[11] Jyothi P, Basavaraj MC, Basavaraj PV. Bacteriological profile of neonatal septicemia and antibiotic susceptibility pattern of the isolates. J Nat Sci Biol Med 2013;4(2):306-9.

[12] Khan SN, Joseph S. Neonatal sepsis: antibiotic sensitivity \& resistance pattern of commonly isolated pathogens in a neonatal intensive care unit of a tertiary care hospital, south India. Int J Pharm Bio Sci 2012;3(4):802-9. 
[13] Lamba M, Sharma D, Sharma R, et al. Bacteriological spectrum and antimicrobial susceptibility pattern of neonatal septicaemia in a tertiary care hospital of North India. J Mater-Fetal Neonatal Med 2016;29(24):3993-8.

[14] Kayange N, Kamugisha E, Mwizamholya DL, et al. Predictors of positive blood culture and deaths among neonates with suspected neonatal sepsis in a tertiary hospital, Mwanza-Tanzania. BMC Pediatr 2010;10:39.

[15] Rahman S, Hameed A, Roghani MT, et al. Multidrug resistant neonatal sepsis in Peshawar, Pakistan. Arch Dis Child Fetal Neonatal Ed 2002;87(1):F52-4.

[16] Aletayeb SMH, Khosravi AD, Dehdashtian M, et al. Identification of bacterial agents and antimicrobial susceptibility of neonatal sepsis: a 54-month study in a tertiary hospital. Afr J Microbiol Res 2011;5(5):52831.
[17] Bhat YR, Lewis LE, Vandana KE. Bacterial isolates of early-onset neonatal sepsis and their antibiotic susceptibility pattern between 1998 and 2004: an audit from a center in India. Ital J Pediatr 2011;37:32.

[18] Mhada TV, Fredrick F, Matee MI, et al. Neonatal sepsis at Muhimbili National Hospital, Dar es Salaam, Tanzania; aetiology, antimicrobial sensitivity pattern and clinical outcome. BMC Public Health 2012;12:904.

[19] Dias E, Brain P. The bacterial profile of neonatal septicaemia in a rural hospital in South India. J Clin Diagn Res 2010;4:3327-30. 